\title{
Preliminary Study of the Knowledge Improvement for Professional Practice through Collaborative-Reflective Supervision
}

\author{
A. Sudarsyah \\ Universitas Pendidikan Indonesia \\ sudarsyahasep@upi.edu
}

\begin{abstract}
The aim of this qualitative study is to explore school conditions and the needs of teacher's professional knowledge in practice through Collaborative-Reflective Supervision (CRS) at one elementary school under the guidance of the Indonesian University of Education. This research, a preliminary study, looked for the empirical evidence about school conditions in general and needs of teacher's professional development which was suitable with the CRS model. The result of a study is constructed as scaffolding for a component of the CRS. The data were gathered based on in-depth interview and participative observation with one of the principal and school members. The problem of teacher professional development is used to be implemented in perspective, directive, and short tornadoes. Consequently, it must be changed to become more collaborative, constructive, school-based and collegial in their relationship. In this model, the activity of the supervisors (principal and master teacher) is facilitating teachers to learn together in improving professional, practical knowledge by rethinking their experience in order to design better instruction in future. Reflection process is started by responding particular problems which arose in the classroom and expanding more knowledge and apply in professional practice situation. The CRS should see a collaborative, constructive, school-based and collegial relationship. The results of the study indicate that the school has the features available for condition to implement the CRS and fulfill the needs of teacher professional development. All of the results can be constructed as the components of the CRS model which consist of reflection process, distributed function of supervision, structural leadership of the principal and collegial relationship.
\end{abstract}

Key words: reflection, supervision, collaborative, practical professional knowledge

\section{INTRODUCTION}

The improvement of the teacher knowledge in their professional practice still had been implemented through in-service training and considered to be more perspective; directive; didactive; and short-term [1]. It is contrary to the expected conditions from CRS which requires the collaborative, constructivist, school-based, and collegial climate [2]. In supervision study, these expected conditions are called collaborative and reflective $[3,4]$.

This study represents the initial phase to test models of CSR. CRS implementation requires particular schools which fit the conditions and requirements for CRS. The school characteristics should be consisted of (1) Its collaborative learning experiences; (2) Its facilities for teachers to learn together; (3) Its expert teacher; (4) Its positive attitudes and expectations towards reflection; and (5) Its partnership performance.

Other research results show that CSR can only be implemented at school which have formed a collaborative culture characterized by (1) spontaneous, (2) voluntary, (3) oriented development, (3) take place in time and space formal or informal, and (4) unpredictable [5]. It is more likely to be a collaborative cultural because the model of CRS already has a culture of learning together in some schools. On the other hand, in other schools, it is found that culture is not yet formed. Characteristics are a bridge to build a learning community of teachers in schools. Therefore, the preliminary study aims to identify schools which already have the needed characteristics.

To judge from the concept of education supervision, teachers at school are used to get the professional development through inspective supervision. This is often called a model of prescriptive supervision. School, which builds a culture of learning together, got professional development through learning together in solving problems of the classroom. This learning together activity in solving problems is often called collaborative supervision. The prescriptive supervision did not want teacher to become self-regulated, as it failed to create a lasting impact on her teaching. In contrast, the collaborative supervision gives teacher the opportunities to change the way they teach. [6]

\section{METHOD}

As one of the R \& D stages, the method of this study is a case-study which is based on in-depth interview and participative observation with 16 staff members in the school.

In brief, the overview for the establishment of the elementary school at Indonesian University of Education was inaugurated by The Ministry of National Education, Republic of Indonesia in October 20, 2008. This elementary school had been implemented professional development by School Based Lesson Study (LSBS) which aimed to improve teachers' competencies. It is becoming the basis to the development of CRS which prioritizes the teacher group activity to improve their competencies in reflecting professional practical knowledge. Data were collected refer to the research focus: (1) the schools have a collaborative learning experience; (2) the schools have facilities for teachers to learn together; (3) the schools have an expert teacher to be a facilitator; (4) teachers have positive attitudes and 
expectations towards reflection; and (5) The schools are already used to perform a partnership.

Findings about empirical condition of professional practical knowledge will become scaffolding that shapes the initial model of CRS. This research applies one of the R \& D stages: research and information collecting. This study has been done in private school which is contextually different to the public school. The differences are laid on the teacher employment status. There were contract teachers in private school and civil teachers in public school. Those two group of teacher's employment status differences would create a different context that would also affect to the different primary potency.

\section{FINDINGS}

\section{A. Initial condition of the professional, practical knowledge}

1) Collaborative Learning.

Collaborative Learning. In this school, the collaborative learning has been developing since 2008 . Design of learning implementation or document of lesson plan, is one of the professional practical knowledge having main components for instances the instructional goals, the instructional process and the instructional evaluation [7]. Collaborative learning is implemented among teacher at the $1^{\text {st }}$ grade, $2^{\text {nd }}$ grade, $3^{\text {rd }}$ grade teachers. For subject teachers, they are individually designing the RPP.

The practice has been implemented in the second semester, from 2014 to 2015 . Teacher discussed related to "how does delivery system of content work in thematic instruction" (field note on 4 June 2015). The collaborative learning processes are described in the interview notes with the teacher whose name initially as follows:

"School planned the work programs at the first semester. Staff members involved to plan lesson, specifically teachers of the $1^{\text {st }}$ grade, $2^{\text {nd }}$ grade and $3^{\text {rd }}$ grade (BSO).

"Lesson plan was designed by teacher after teaching and learning activity schedule, and so on. It had been arranged together between principal and teachers. Lesson plan was described into specific components of teaching objective, instructional strategy and evaluation method. After that, lesson plan was designed together by group of teachers at all grade level, but subject teachers were doing it individually" (ASP).

"In our school, lesson plan had been planned before beginning the teaching and learning activity. It involved all teachers in team work (from $1^{\text {st }}$ grade to $3^{\text {rd }}$ grade) and subject teacher" (BKN).

\section{2) Learning Together Activity.}

Teachers always have their discussion activity on Friday at 13.00 if it is not a holiday. The collaborative learning materials include materials which relate to the teacher professional, practical knowledge such as teaching and learning activity plan, learning implementation plan and other important things related to school development (validated by teacher document list).

3) Source of professional assistance in collaborativereflective.

Professional assistance means the principal and the colleagues who could give teacher information when they have difficulty or even need answers to their curiosity. In other days, not in Friday, rooms are set in many ways to facilitate teachers sharing information related to their professional knowledge practically. For example, they arrange rooms among the $1^{\text {st }}$ grade room for the $3^{\text {rd }}$ grade room close each other.

\section{4) Professional Development Practice by School} Supervisor (school supervisor).

Professional practice knowledge development is working with a school supervisor as following steps (1) observing instruction process implementation by Teacher Performance Assessment Analysis (TPAA) instrument; and (2) discussing the observation result aimed to let teachers know their weaknesses and strengths of their teaching performance. The supervisor is responsible to educate at least 10 schools and 15 schools. At first, the teachers are likely to expect that it can provide benefits for their professional practice knowledge, but in fact it seems very impossible to be implemented due to limited time. This directive supervision refers to the number of general teacher performance criteria to the summative evaluation through observation. As observation result, Supervisor gives the teacher weakness and strengths judgement based on their criteria.

This professional development practice has not regularly been implemented yet, or has not accustomed yet by the principal due to limited time, so the principle usually replacing this practice by seminar and in-house training to develop teacher knowledge. These activities are mostly held in learning and teaching activity. Teachers expect the activities are held after learning and teaching activity so students still having their time to learn and teach as well.

5) Teacher Expectations of The Reflection Activity.

All teachers agreed that school vision was set to develop student's potency. As a supervisor, School principal has their legality to guide teacher about vision, mission and goals in school. The principal, as a structural leader, invited teacher's participation to formulate the vision, mission and goals in school. The principal has a role to negotiate, compromise and to cultivate values, whether or not those are needed to be done in the process of achieving the vision, mission, and goal in school. On the basis of the structural interest, principal holds the scheduled activity to develop teacher's professional practice. For some teachers, this activity do not contribute enough to the development of their professional competency so they expect that principal to take the initiative to develop their reflection capability. They revealed their expectation as follows:

"The teachers need sustainable training guidance to improve their competency and to lead the innovation in their competency improvement". (RN)

"A school leader, principal, becomes a central attention to develop school's policy in teacher professional improvement. One of the ways in improving teacher competency is a reflection from principal to the teacher's learning preparation process in the classroom. The reflection should be implemented because it can give teachers the opportunity to be a better teacher". (PT)

"Very important, teachers would never know their detail teaching weakness, unfortunately there was no 
observer who could help to reflect the instruction process. Therefore, observation would find the effective learning process and improve student learning achievement." (BNU)

Based on the interview above, it can be concluded that teacher disposition to reflect their professional practice cannot be implemented without principal seaports. This disposition is teacher's awareness for the importance of professional, practical knowledge through reflection activity.

\section{B. The teacher needs in developing knowledge of the professional practice}

1) Expectation of the sustained in-house training activity.

The expectation of the sustained in-house training activity is revealed by teacher's respond to the result of the Teacher Competency Test (TCT). Nationally, the data from all teachers from early childhood school to senior high school, reveals that the average of their TCT result is still in the low level. The teacher's TCT average in 2012 stood at 42.25 with the highest score at 97.00 and the lowest score at 1.00. The teacher expects that the routine in-house training activity for all teachers is sustainable held after student's learning and teaching process to ensure the student still have their right to learn, as the following response:

"Based on those facts (the result of TCT), teacher must regularly be trained to develop their professional competency and optimize the student's competency as well. There should be formed the evaluation teams who responsible to evaluate the performance of teachers." (RN)

"Professional teachers are should be proven not only by the result of TCT but also by their teaching quality in the classroom. It is difficult to get the high TCT scores. It means to be a professional teacher is difficult, but students must have their right to get a good education at the same time. So, training and educational development are needed for further education." (BNU)

"We have to realize that teachers nowadays are not being the exemplary teacher yet who could compete and could adapt to the scientific development so the government must be taking some appropriate actions to solve this problem for example by the sustainable training." (BW)

\section{2) The theory and practice are needed for reflection.}

The reflection is an activity for the information acquired through the collaboration process which known as the needs of practical knowledge. The reflection activity is implemented through the development of the formal knowledge, such as theory, concept and instruction method. The finding was supported by the quote from questionnaire below:

"Training is needed by teachers to improve their knowledge. This aimed to produce qualified teachers." (HD). Those below are teacher's opinion about teacher lack of Teacher Competency Test (TCT) scores:

"TCT is the only score to reflect teacher's cognitive capacity. It does not measure completely. In fact, there are some immeasurable score of scale, but the teacher who agreed the TCT can improve teacher competency in their professional development. Teacher have to learn, comprehend and find appropriate method which needed nowadays." (PT)

The internal reflection is based on teacher's own professional experience. The external reflection is based on their professional experience evaluated by each teacher. The first reflection step is aimed to cope their good feelings with the experience so teachers could be creating a positive atmosphere and forget the negative feelings. It was proven by those following teacher's opinions below:

"We have to realize that teachers nowadays are not being the exemplary teacher yet who could compete and could adapt to the scientific development so the government must be taking some appropriate actions to solve this problem for example by the sustainable training." (BW)

"The criteria's of the professional and qualified teachers are linked each other which means that their professional and quality should not only been scored by the TCT but qualified teaching implementation as well. Although, lack of TCT scores showed that to develop teacher professional competency is difficult, it still must be implemented to create the students to be a better generation." (BSI)

"Knowing the lack average of the TCT result, I feel worry, how can we create, the better generations with this limited teacher competency. It is needless to say, in school, that teacher's professional development is needed." (EMR)

\section{3) Reflection as a Feedback.}

Reflection was started by self-reflection in teaching, then it is confirmed by a principal or master teacher feedback in the collaborative process.

"The guidance from principal or master teacher given by doing the routine training to train teachers the new competency and develop teachers' competency that shown by the teacher's capability to innovate, Those are the ways to solve this lack of teachers' competency problem." (RN)

"It is important to the principal that teachers are facilitated to build their strengths and address their weaknesses in learning and teaching activity. It would create a positive feedback for them." (HD)

The activity to build off of teacher strengths and address their weaknesses is applied and evaluated by others. So that, reflection is emphasized as an instrument to give the feedback from the other teachers (or the principal) about their knowledge of professional practice.

4) Self reflection is confirmed through feedback in the collaborative process.

As a feedback instrument, self-reflection is confirmed through other feedbacks in a collaborative process. It is started by realizing self-weakness is one of the reflection activities. As follows open questionnaire was cited:

"Back to the teacher's status, whether she or he is a contract, civil, or private teacher, however the status of their employment could affect as well as their moral responsibility in their professional performance practice. Teachers have enough administrative skills. The most important is their moral responsibility. It is needless to say that many teachers nowadays are thinking that their 
professional responsibility is only to teach. However, their responsibilities are more than that." (SNT)

"Becoming a professional teacher is not as easy as it seems. By the interaction frequency with students as a teacher, I can build off of student strengths and address their weaknesses. Also, I try to build a good communication to student's parents, teachers, and learning environment itself." (EMR)

\section{5) Teacher's attitude to the learning by experience.}

Generally, teachers agree that "experience is the best teacher". This has become an evidence of teacher's disposition relates to their willingness to be more realizing their weakness and strengths of their professional practice performance. Descriptions shown by the questionnaire: "experience"; "better to learn from mistakes insha Allah" (EMR); "experience could be improving other capabilities" (PT); "We can learn from the weakness and strength" (HD); "Yes or no is depend on the teacher willingness to change" (BW); "create the innovation to develop instruction quality" (IP); "Learn from the experiences was a self-evaluation" (TN); "Teachers can learn from their experience and student's experience as well" (IMN); and " After lesson study teachers can apply the reflection" (AK).

\section{6) The Practical Knowledge Requirements.}

The practical knowledge requirements are sets of abilities in setting the instruction goal, indicator of the goal, and content delivery system (method). There are two teacher categories based on their practical knowledge needs. The first group is a group of teachers who master in developing the lesson plan. They are DT; DR; IR; RN and EMR. The second group is a group of teachers who consider that they have not mastered yet in: (1) knowing each student's character and needs and to set the learning indicator that fits by all students (AGS); (2) choosing the appropriate indicator keywords and deciding learning method (TN); (3) deciding learning method (HD); (4) developing learning indicator (PT); and designing a thematic instruction (BSO). Teachers who are not in those two groups have difficulty to provide the learning media which caused by school limited facility

\section{7) Partnership to Enhance The Participation.}

Partnerships based on teacher group are categorized in three categories, (1) Partnership among teachers in one school; (2) Partnership with the experts; and (3) Partnership in learning community. The teacher needs the new information to improve their professional practice (by expert partnership) because someday teacher would be facing some limited information related to the professional practice for their knowledge development (by teacher partnership). The learning community partnership has not been developed yet. Based on the observation and interview, teacher partnership and qualified-teacher partnership is going to develop.

\section{DISCUSSION}

\section{A. Teachers' collaborative learning has been developed.}

The collaborative supervision for the knowledge development of the teacher professional practice requires collaborative potency. "Even though there may be some opportunities for isolated work and reflection, most of the effective professional development occurs when there are meaningful interactions not only among teachers themselves, but also between teachers, administrators, parents and other community members" [8]. The basic potency, collaborative professional development activity has been the main activity in developing the CRS model.

\section{B. There are space and time to implement the learning together activity.}

The Elementary School in Indonesian University of Education had been setting the collaborative supervision schedule every Friday from 2014 to 2015 but almost all teachers have limited time to involve in directive supervision activity by school supervisor due to their at least 24 hour teaching responsibility. Teachers also confused to manage their time, grasp materials and master teacher competency at the same time, isolated feeling and organizational problems are the main problem that must be solved by developing the CRS model [9].

\section{The Professional role in collaborative-reflective supervision.}

CSR requires a partner to share the information about reflected object. Everyone who can be a partner are the principal, the master teachers and the experts. Reflection can be implemented by the interactions between humans. Teachers are actively involved to evaluate, observe and reflect their instructional or more constructivist than transmission model. It relates to be facilitated in the development of school-wide professional learning communities [10].

\section{Teacher's expectation of reflection activity.}

Teacher's expectation of reflection activity indicated their readiness to live in their profession, attend their positive feelings and willingness to evaluate what they have been doing. The reflection is implemented in three steps. The first, returning to experience, teachers are involved in the experience. The second, attending to feelings, to gather teacher's positive feelings. The third, reevaluating experience, teachers re-evaluate their experience, process and integrate their relevant background knowledge to the new knowledge in their conceptual scheme and adapt the scheme as a repertoire of behavior.

\section{E. The theory and practice for the reflection activity.}

The informal knowledge attended in reflection process which commonly involved in professional practice when teacher reflect their professional practice experience. Also, in this case, formal knowledge contributes to evaluate the experience. It means both knowledge for practice and knowledge in practice or tacit and explicit are integrated into reflection activity [11]. The teacher begins to reflect their experience (tacit or knowledge in practice) and evaluate with their prior formal knowledge at the same time.

\section{F. Reflection as a feedback instrument.}

Feedback is the one of the important instruments in collaborative supervision. Feedback must be raised in every sharing activity. Feedback instrument in collaborative model and supervisor roles are working together with the teacher but not to direct them. Supervisor always asks teachers together, making a decision. This model is believed that in teaching there is mostly about the 
process to solve a problem which requires some discussion between teacher and supervisor [12].

\section{$G$. Self reflection confirmed through feedback in the collaborative process.}

The individual reflection is a subjective reflection process when people build the view about their world which affected by their biography such assumption, belief, perception and the way they interpreting and acting based on experience. It is hard to develop a self-biography in the individual reflection process so dialogue or collaborativereflective provides the solution to communicate selfbiography to others so that they learn to construct the knowledge in social interaction [13].

\section{H. Teacher's positive attitude in learning by experience.}

Reflective teacher is a teacher who always considers their behavior with the consequence. To become a reflective teacher, They have to learn these reflective teacher characteristics: (1) open-minds, perceptive to the new ideas; (2) wholeheartedness, persistence to find out and try every new thing; and (3) responsibility, realize that everything has the consequence [14]

\section{Practical knowledge is needed to plan, implement and evaluate the instruction.}

Teacher's professional, practical knowledge is an onthe-spot knowledge in their instructional practice. It is about the way they teach. The level of confidence that teachers have when they first enact their role as a teacher will be greatly influenced by: (1) how well teachers are mentally prepared; (2) how caring teachers have thought about their responsibility as a role model for their students; and (3) how teachers will question their learners.

\section{J. Partnership to enlarge participation.}

The partnership begins between teachers and principal or master teacher to collaboratively direct with the expert involvement of the outsider of school. The importance of the external partnership helped to maintain the teacher's initiative and to offer another teaching perspective. It has to be emphasized that supervisor and teachers are totally involved in the process, so that would enact the connection of partnership. [15]

Based on the result of preliminary study, the elementary school of the Indonesian University of Education has the conditions in need to improve teacher's professional practical knowledge which is suitable with CRS. The figures of CRS are (1) Structurally, the principal has been inviting the teacher' participation to make decisions about how to develop teacher professional in school; (2) The principal has been distributing the function of supervision to the master teacher to be recognized by another teacher in community; (3) The teachers have been re-thinking their instructional experiences, developing their open-mindedness, and evaluating their experiences to improve teaching and learning in classroom in future; (4) The partnership have been developed with both external expert (external) and master teacher (internal); and (5) The collegial relationship have been built to share experiences with other teachers. The features could construct in the component of CRS model that will be developed in the section two of the research:

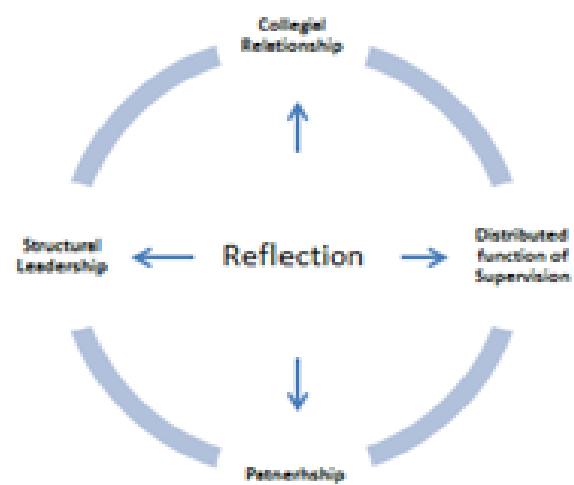

Fig. 1.

Interconnections of Component Collaborative-Reflective Supervision

\section{CONCLUSION}

Based on the result of the preliminary study and literatures, The elementary school of the Indonesian University of Education potentially becomes a place to develop teacher's practical knowledge through collaborative-reflective to be more (1) collaborative, (2) constructivist, (3) school-based, and (4) collegial.

\section{REFERENCES}

[1] Christopher D., Judyth, S. International Handbook on the Continuing Professional Development of Teachers;2004.England: Open University Press.

[2] Sailesh Sharma, Marohaini Yusoff, Sathiamoorthy Kannan. Instructional Supervision in Three Asian Countries-What Do Teachers \& Principals Say? International Conference on Education and Management Technology;2011,13: 34-38.

[3] Tabitha L. Young , Glenn W. Lambie , Tracy Hutchinson \& Jacqueline Thurston- Dyer. The Integration of Reflectivity in Developmental Supervision: Implications for Clinical Supervisors, The Clinical Supervisor; 2011.30:1, 1-18

[4] Marvarene Oliver , Kaye Nelson \& Kathy Ybañez Systemic Processes in Triadic Supervision, The Clinical Supervisor, 2010. 29:1, 51-67,

[5] Hargreaves.Changing Teachers, Changing Times. London: Wellington House; 1994. 192-193 pp.

[6] Goodson \& Hargreaves ed. Teachers Matter; 2006. England: Open University Press.

[7] Degeling, M., Prilla, M. Improving Social Practice: Enhancing learning experiences with support for collaborative reflection. CEUR Workshop Proceedings;2012. 931, 133-146.

[8] Villegas-Reimers, E. Teacher professional development: an international review of the literature. Unesco: International Institute for Educational Planning; 2003. www.unesco.org/iiep.

[9] Mcgregor,Cartwright, L. Developing Reflevtive Practice;2011. England: Open University Press. 199 p.

[10] Hord, SM. Professional Learning Communities: Communities of Continuous Inquiry and Improvement. Journal of School Leadership,1997.40(1), 58-59.

[11] Seamus Hegarty. Teaching as a Knowledge-based Activity, Oxford Review of Education; 2000. 26:3-4, 451-465.

[12] Chen, C. W.-Y., \& Cheng, Y. (2013). The Supervisory Process of EFL Teachers: A Case Study. The Electronic Journal for English as a Second Language;May 2013. 17(1), 1-21.

[13] Brockbank, A., \& McGill, I. Facilitating Reflective Learning Through Mentoring \& Coaching; 2006. London: Kogan Page.

[14] Mcgregor, Cartwright, L. Developing Reflevtive Practice. England: Open University Press; 2011. 4 p.

[15] Costantini, R. (2008). The Influence of Professional Learning Communities on Teachers' Levels of Self-Reflections; 2008, University of Arkansas at Little Rock. 